\title{
Production of recombinant protein by a novel oxygen-induced system in Escherichia coli
}

\author{
Antonino Baez ${ }^{1}$, Nadim Majdalani ${ }^{2}$ and Joseph Shiloach ${ }^{*}$
}

\begin{abstract}
Background: The SoxRS regulon of $E$. coli is activated in response to elevated dissolved oxygen concentration likely to protect the bacteria from possible oxygen damage. The soxS expression can be increased up to 16 fold, making it a possible candidate for recombinant protein expression. Compared with the existing induction approaches, oxygen induction is advantageous because it does not involve addition or depletion of growth factors or nutrients, addition of chemical inducers or temperature changes that can affect growth and metabolism of the producing bacteria. It also does not affect the composition of the growth medium simplifying the recovery and purification processes.

Results: The soxS promoter was cloned into the commercial pGFPmut3.1 plasmid creating PAB49, an expression vector that can be induced by increasing oxygen concentration. The efficiency and the regulatory properties of the soxS promoter were characterized by measuring the GFP expression when the culture dissolved oxygen concentration was increased from 30\% to 300\% air saturation. The expression level of recombinant GFP was proportional to the oxygen concentration, demonstrating that pAB49 is a controllable expression vector. A possible harmful effect of elevated oxygen concentration on the recombinant product was found to be negligible by determining the protein-carbonyl content and its specific fluorescence.

By performing high density growth in modified LB medium, the cells were induced by increasing the oxygen concentration. After 3 hours at 300\% air saturation, GFP fluorescence reached 109000 FU (494 mg of GFP/L), representing 3.4\% of total protein, and the cell concentration reached $29.1 \mathrm{~g} / \mathrm{L}$ (DW).

Conclusions: Induction of recombinant protein expression by increasing the dissolved oxygen concentration was found to be a simple and efficient alternative expression strategy that excludes the use of chemical, nutrient or thermal inducers that have a potential negative effect on cell growth or the product recovery.
\end{abstract}

Keywords: soxS promoter, Protein oxidation, GFP oxidation, High cell density, Carbonyl groups

\section{Background}

It has been established that in response to high dissolved oxygen of 300\% air saturation, E. coli activates the SoxRS regulon which activates the transcription of the soxS and the $\operatorname{sod} A$ genes [1]. The $\operatorname{sod} A$ gene encodes the manganesesuperoxide dismutase (SOD), which reduces the oxidative stress caused by molecular oxygen, allowing the cells to grow uninterrupted at $300 \%$ oxygen [2,3]. Baez et al. [1] showed that in response to high oxygen concentrations, soxS expression is increased 16 fold, making it a possible candidate for inducing recombinant protein expression in

\footnotetext{
* Correspondence: yossi@nih.gov

${ }^{1}$ Biotechnology Core Laboratory, National Institute of Diabetes and Digestive and Kidney Diseases, National Institutes of Health, Bethesda, MD 20892, USA Full list of author information is available at the end of the article
}

response to high oxygen concentrations. Expression of recombinant proteins is often achieved by coupling the recombinant protein gene to promoters of genes that are activated in response to the presence or absence of a specific factor. Among the known examples for such couplings are the expression systems of the methylotrophic yeast Pichia pastoris, where the heterologous gene is coupled to the methanol-activated AOX1 promoter [4]; the glucose-depletion activated expression system of Saccharomyces cerevisiae [5]; and the arabinose inducible ara $P_{\mathrm{BAD}}$ promoter in, E. coli, [6]. The activation of the soxS gene by increasing dissolved oxygen levels could be an additional way for expressing recombinant proteins from $E$. coli without affecting cell growth or metabolism since it does not rely on starvation stress 
induced by nitrogen, phosphate, or amino acids limitation [7]. Expression of recombinant proteins using high oxygen concentration has attractive properties such as precise control of the induction timing and the elimination of the inducer in the final product or the waste effluents of the bioprocess, making this strategy potentially suitable for production of pharmaceutical-grade proteins [8]. In this report, we describe the expression of recombinant green fluorescent protein from $E$. coli by using the soxS promoter and molecular oxygen as an inducer. The expression was compared to other induction procedure and the effect of oxygen on bacterial growth and protein integrity was evaluated.

\section{Results}

Production of GFP by oxygen-induced promoter in batch growth

The production of recombinant green fluorescent protein (GFP) under the control of the soxS (pAB49) and lac (pAB828) promoters is shown in Figure 1. E. coli AB1157, harboring pAB49, was grown initially at a dissolved oxygen $\left(\mathrm{dO}_{2}\right)$ concentration of $30 \%$ air saturation in batch cultures. One hour after inoculation, the $\mathrm{dO}_{2}$ concentration was decreased to $0 \%$, maintained at $30 \%$ or increased to $300 \%$ air saturation and GFP fluorescence was measured (Figure 1A). When the $\mathrm{dO}_{2}$ concentration was kept at $0 \%$, GFP fluorescence was $573 \mathrm{FU}$. At $30 \% \mathrm{dO}_{2}$ air saturation, GFP fluorescence was $1585 \mathrm{FU}$, and at an oxygen concentration of $300 \%$, GFP concentration rose to 4500 . Thus, the expression level of recombinant GFP increased 7.8-fold with the increased of the dissolved oxygen concentration. No significant changes $(p=0.05)$ were observed in the specific growth rate of the culture at $30 \%$ $(1.08 / \mathrm{h})$ and $300 \%(1.00 / \mathrm{h})$ of $\mathrm{dO}_{2}$ (Figure $\left.1 \mathrm{~B}\right)$.

GFP expression under the control of the soxS promoter was compared to its expression under the IPTG-inducible lac promoter. The expression levels from plasmid pAB828 ( $\mathrm{p}_{l a c}-\mathrm{GFP}$ ) and plasmid pAB43 (promoter-less GFP) are shown in Figure 1C. The maximum GFP expression by the lac promoter, with $0.5 \mathrm{mM}$ IPTG, was $20170 \mathrm{FU}$ at cell concentration of $3.6 \mathrm{~g} / \mathrm{L}$ (Figure $1 \mathrm{C}$ and D). In comparison, the maximum GFP expression in bacteria harboring the promoter-less plasmid (pAB43) was $730 \mathrm{FU}$ which is close to the $573 \mathrm{FU}$ seen with the un-induced $\left(0 \% \mathrm{dO}_{2}\right)$ culture of cells carrying the $\mathrm{p}_{\text {soxs }}$ plasmid. This construct also showed no response to IPTG as expected (Figure 1C). Western blots of soluble and insoluble fractions were also assayed (data no shown) and GFP was only detected in the soluble fraction of the proteins [9]. To verify that GFP fluorescence intensity was proportional to the amount of GFP produced, western blots were done and results are shown in Figure 2. The highest amounts of GFP were
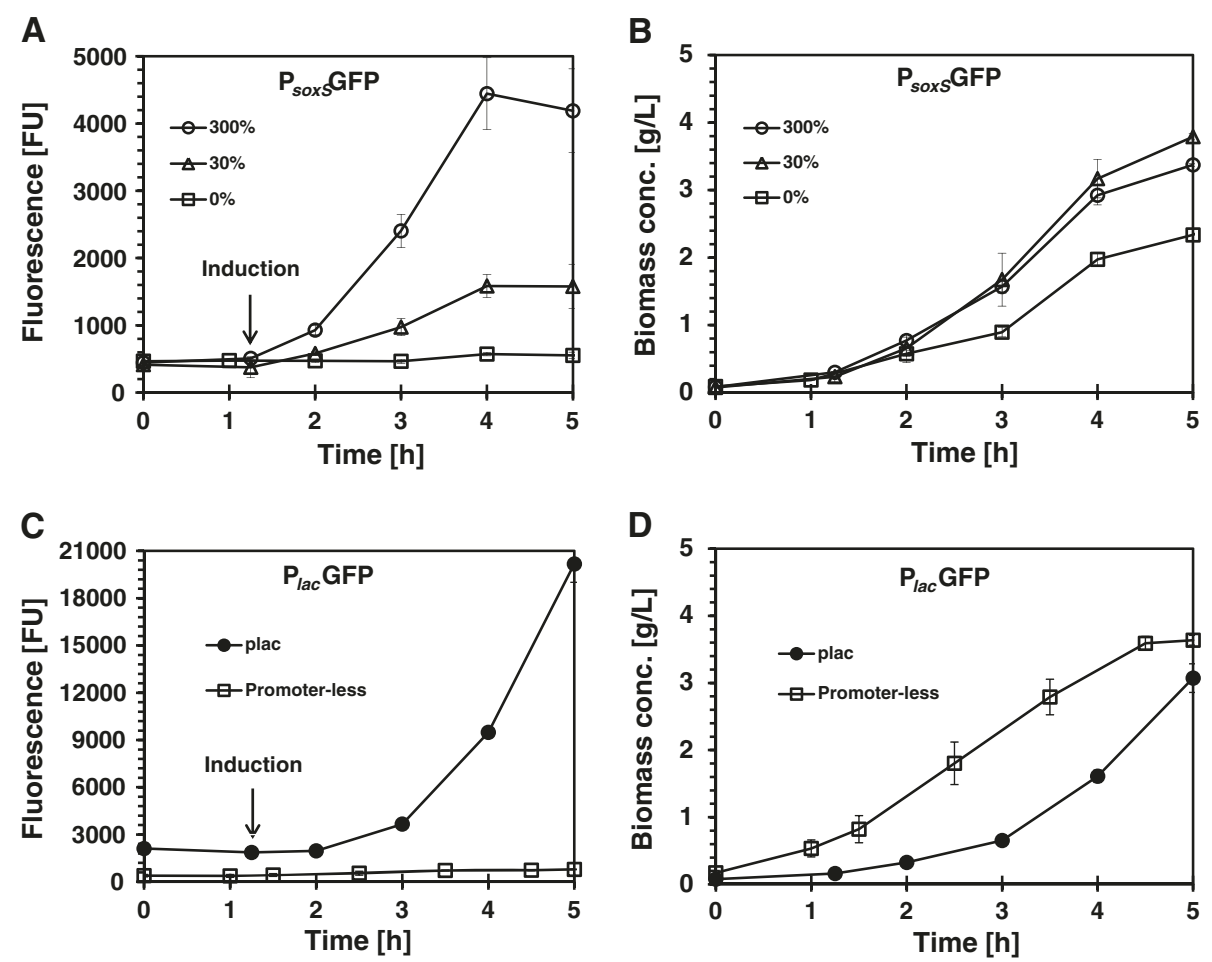

Figure 1 E. coli AB1157 growth and GFP production: A, B pAB49 (soxS promoter induced by increasing dO ${ }_{2}$ up to $300 \%$ ) $C$, D pAB828 (lac promoter) and pAB43 (promoter-less plasmid). All cultures were controlled at $30 \%$ of $\mathrm{dO}_{2}$ except those labeled as $300 \%$ or $0 \%$. The arrow indicated the time when oxygen or IPTG were added to the culture, the error bars show the standard deviation of experiments performed in triplicate. 


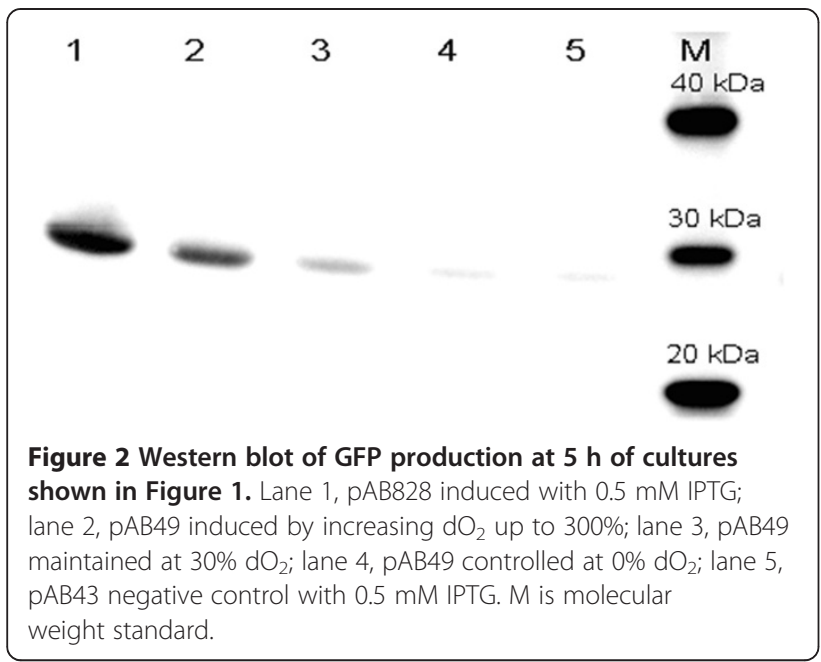

produced by pAB828 induced with IPTG (Figure 2 line 1 ). For the soxS system (pAB49), production of GFP correlated with varying oxygen concentrations (Figure 2 lines 2, 3 , and 4). Since the fluorescence of the medium was 380 FU and there was almost no observable GFP signal in line 4 (Figure 2), it can be concluded that the 573 FU produced by soxS-promoter at $0 \% \mathrm{dO}_{2}$ come from the background effect of the cells and the medium.

The amount of GFP produced was also determined by ELISA; it was calculated that GFP represents $5.1 \%$ of total protein produced by cells harboring pAB828 and $1.5 \%$ by cells harboring the soxS promoter when it was done in batch and $3.4 \%$ when it was done in fed batch growth (Table 1). Dividing the fluorescent signal by the amount of GFP produced, specific activities were estimated for both expression systems: $13716 \mathrm{FU} / \mu \mathrm{g}$ of GFP was estimated for pAB828 plasmid and $10736 \mathrm{FU} / \mu \mathrm{g}$ of GFP for the soxS promoter plasmid (Table 1).

Since high $\mathrm{dO}_{2}$ concentrations can increase the intracellular reactive oxygen species [1], the possible effect of the oxygen shift on the integrity of the recombinant protein was evaluated. The protein-carbonyl contents of fresh fermentation samples from pAB828 cultures controlled at $30 \%$ and $300 \% \mathrm{dO}_{2}$ were analyzed using the Oxyblot system to detect protein oxidation (Figure 3). Number of bands showed a pattern of oxidation already appeared at $30 \% \mathrm{dO}_{2}$. This pattern does not seem to change with higher oxygen concentrations and the lack of oxidized bands at $27 \mathrm{kDa}$ indicates that the recombinant GFP produced at normal or high oxygen concentrations either has no carbonyl groups or they are below detectable levels. The specific fluorescence of the GFP proteins produced at $30 \%$ and $300 \% \mathrm{dO}_{2}$ were similar (Table 1): $13397 \mathrm{FU} / \mu \mathrm{g}$ for the culture exposed to $30 \% \mathrm{dO}_{2}$ and 14410 for the culture exposed to $300 \% \mathrm{dO}_{2}$, an indication that the oxygen shift did not affect the integrity of the GFP produced.

\section{Production of GFP by oxygen-induced promoter in fed-batch growth}

To test the functionality of the oxygen-induced system, high density fed-batch culture of E. coli AB1157 bearing pAB49 was performed by adding glucose exponentially as shown in Figure 4A. After five hours growth, the exponential feeding was initiated to maintain a specific growth rate of $0.35 / \mathrm{h}$. One hour after feeding was initiated; GFP expression was induced by increasing the $\mathrm{dO}_{2}$ concentration from $30 \%$ to $300 \%$ air saturation. After 3 hours at $300 \%$ air saturation, GFP fluorescence reached $109000 \mathrm{FU}(494 \mathrm{mg} / \mathrm{L})$ representing $3.4 \%$ of the total protein and the cell concentration reached $29.1 \mathrm{~g} / \mathrm{L}$ (DW). The medium fluorescence was only $4.4 \%$ of the total signal (Figure 4A). The specific fluorescence reached at $9 \mathrm{~h}$ of culture was found to be $11030 \mathrm{FU} / \mu \mathrm{g}$ of GFP produced, similar to the value obtained in the batch growth. The cell growth did not stop after induction and acetate accumulation reached 7.1 g/L (Figure 4B).

\section{Discussion}

The current methods for recombinant protein production in $E$. coli are based on the addition of chemical inducers, temperature shift and nutrient addition or depletion. These methods have their drawbacks: the addition of chemical inducers, such as IPTG can be costly and can contaminate the final product $[10,11]$; temperature shift can be harmful to the bacteria [12-14]; and nutrient depletion can restrict cell growth or the synthesis of the recombinant proteins $[7,14]$. As a result, there is an ongoing effort to come up with alternative induction systems that do not affect cell growth or recombinant protein recovery and purification processes [8]. In this work, we have shown that the E. coli soxS-promoter expression system can be used to induce recombinant gene expression by increasing the molecular oxygen concentration. The use of molecular oxygen does not negatively affect bacterial

Table 1 Comparison of specific fluorescence of GFP expressed under control of lac (pAB828) and soxS (pAB49) promoters

\begin{tabular}{|c|c|c|c|c|}
\hline Parameter (units) & $\begin{array}{l}\text { pAB828 batch, } \\
30 \% \mathrm{dO}_{2}\end{array}$ & $\begin{array}{l}\text { pAB828 batch, } \\
300 \% \mathrm{dO}_{2}\end{array}$ & $\begin{array}{l}\text { pAB49 batch, } \\
300 \% \mathrm{dO}_{2}\end{array}$ & $\begin{array}{l}\text { pAB49 fed-batch, } \\
300 \% \mathrm{dO}_{2}\end{array}$ \\
\hline Amount of GFP in the total soluble protein (\%) & $5.1 \pm 0.31$ & $4.9 \pm 0.38$ & $1.5 \pm 0.03$ & $3.4 \pm 0.11$ \\
\hline Specific fluorescence (FU/mg GFP) & $13753 \pm 880$ & $14464 \pm 1065$ & $10831 \pm 191$ & $11617 \pm 1048$ \\
\hline
\end{tabular}

\pm refers to the standard deviation between triplicates. 


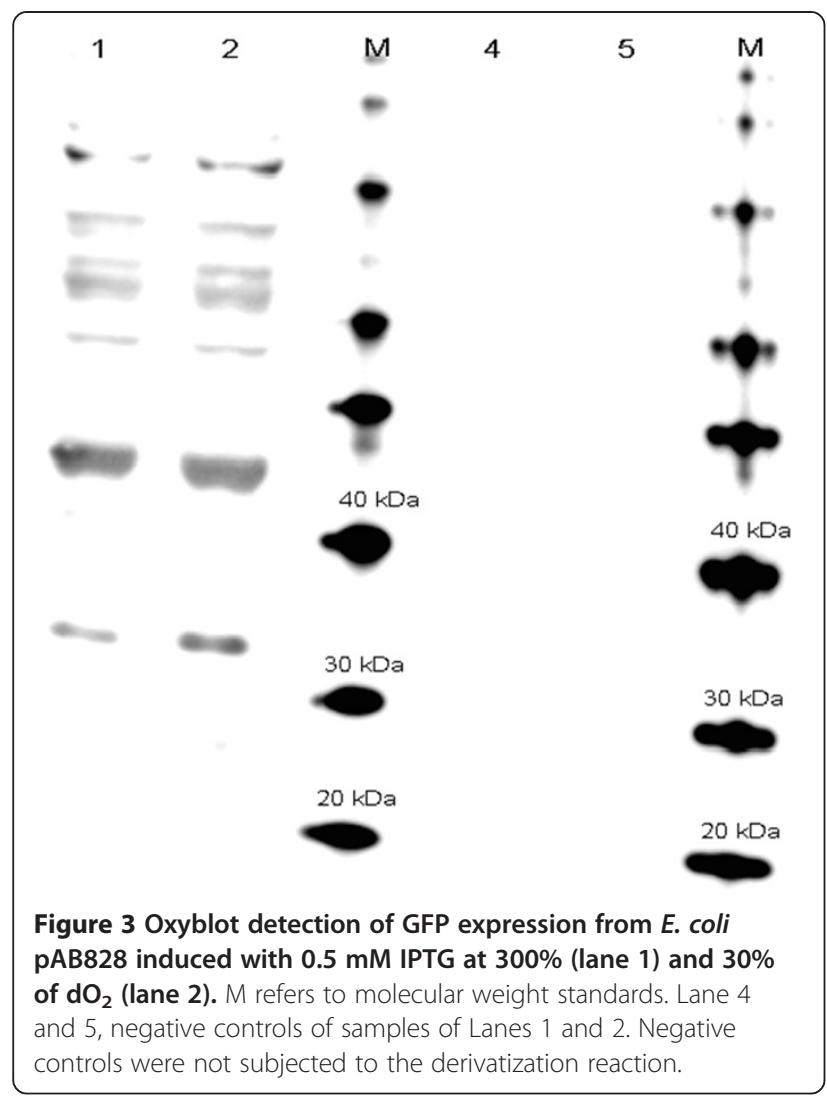

growth nor contaminate the recombinant product or the waste effluents of the bioprocess. In addition, this expression system is dynamically responsive, possibly as the result of oxygen diffusion through the cell membrane, allowing full expression to be achieved in less than 90 minutes [15]. The soxS induction system was tested by expressing GFP at high cell density culture in a 4 L bioreactor induced by increasing oxygen concentration at $\mathrm{OD}_{600}$ of 30 . After three hours, the $\mathrm{OD}_{600}$ reached 78 and the GFP concentration $0.5 \mathrm{~g} / \mathrm{L}$ (Figure 4B). The increased oxygen concentration did not affect cell growth properties [1] nor caused the oxidation of the recombinant product as determined by the Oxyblot assay (Figure 3) which is an indicator of protein oxidation [16]. No signal was detected at or below $27 \mathrm{kDa}$ and no difference in the specific fluorescence was observed.

Similar to the oxygen induction approach demonstrated here, heterologous gene expression by thermoinducible systems is simple and inexpensive. However, the consequences of the heat-shock response as a result of thermo-induction can cause protein denaturation, decrease in specific growth rate, and alteration of central carbon metabolism, presenting a compromise between protein production and stress $[12,14]$. In comparison with the heat induction method, the increased oxygen strategy did not affect the cell growth nor the quality of the
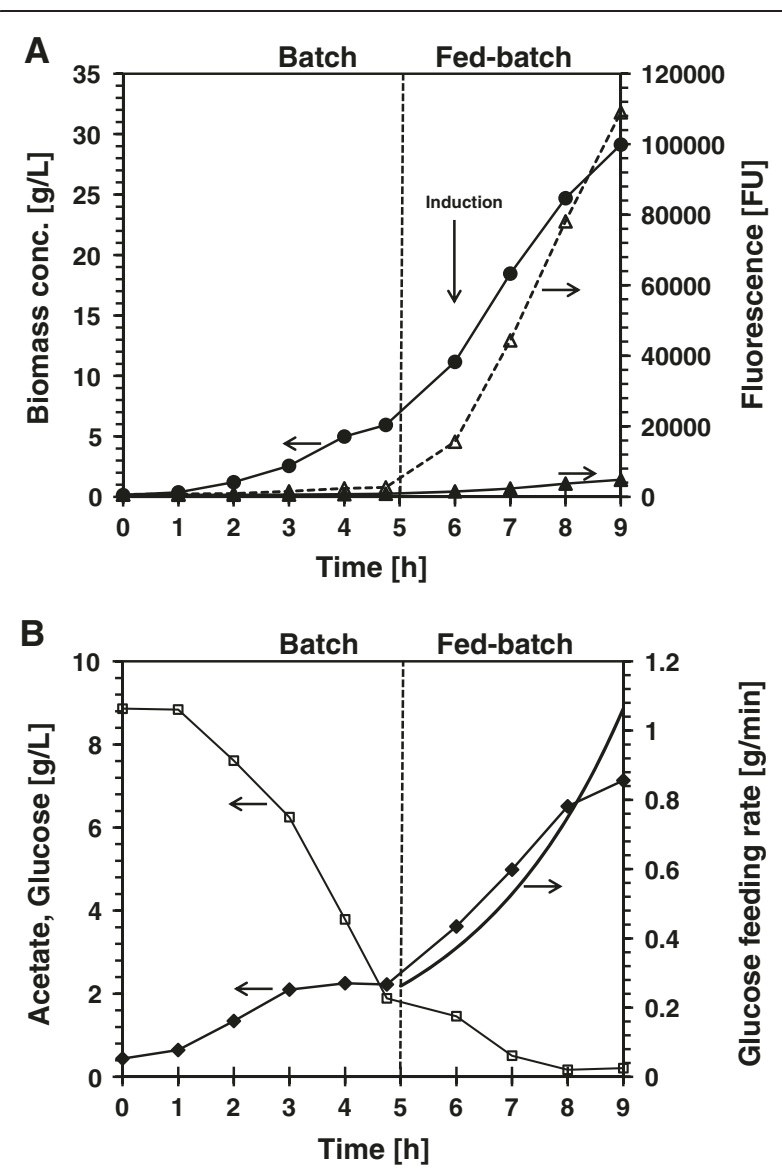

Figure 4 Production of GFP from the E. coli pAB49 (soxS promoter) in fed-batch high density growth. A: Biomass concentration (black circles), total fluorescence (open triangle), and medium fluorescence (black triangle). B: Glucose concentration

(open square), feeding rate (continuous line), acetate concentration (black diamond).

recombinant product. The oxygen induction approach also has an advantage in being tightly controlled and therefore suitable for the expression of potentially toxic products.

Compared with the lac promoter-driven expression, the GFP induction by the soxS promoter was lower but with similar specific activity. Comparing expression levels is difficult since there are different sequences at the ribosomebinding site (RBS) [15]. It is possible that the expression levels of soxS could be increased by using stronger RBS sequences or increasing the strength of the promoter by changing the consensus promoter sequence [17]. Supplying higher concentrations of dissolved oxygen may be difficult and likely expensive when dealing with large bioreactors, but with recent development of oxygen generation technologies $[18,19]$ this method could also be suitable for large scale, however, at present, this technology is limited to applications for laboratory and pilot-scale bioreactors. 


\section{Conclusions}

We have demonstrated a novel recombinant protein expression approach based on induction with high oxygen concentration. This method should be considered as an additional way to express recombinant proteins without affecting cell growth and contaminating the pharmaceutical grade products.

\section{Methods}

\section{Plasmid construction}

All plasmid constructs were derived from the pGFPmut3.1 plasmid (Clontech Laboratories, CA) that carries a $\mathrm{p}_{\text {lac }}$ IPTG-inducible promoter driving the expression of a lacZ leader fused, in frame, to the GFP gene. To make a GFP negative control plasmid (pAB43), the lac promoter on the pGFPmut3.1 plasmid was deleted by digestion with SphI and re-ligation overnight. The ligation mix was cut with BamHI to remove any residual parental plasmid prior to transforming the competent cells. Construction of the oxygen-induced plasmid (pAB49) was done in one step: The lac promoter of pGFPmut3.1 was replaced with the soxS promoter through QuikChange II Site-Directed Mutagenesis (Agilent technologies, CA) with primers soxS-GFP-A and soxS-GFP-B (Table 2). The mega primer soxS-GFP-A contains the native ribosome binding site, soxS promoter region and start codon from E. coli K-12 genome. Because the pGFPmut3.1 plasmid generates two proteins, a lacZ-GFP fusion protein as well as the GFP protein alone, pAB828 was constructed to delete the lac $Z$ leader but maintain the GFP gene under IPTG control. This was done by site-directed mutagenesis (QuikChange II Site-Kit, Agilent Technologies) using primers GFPmutA and GFPmut-B (Table 2). All plasmids were confirmed by sequencing.
Bacterial strain, inoculum preparation, and culture media Escherichia coli strain AB1157 ( $\mathrm{F}^{-}$, thr-1, leuB6, proA2, his-4, thi-1, argE2, lacY1, galK2, rpsL, supE44, ara-14, xyl15, mtl-1, tsx-33) [20] harboring the pAB49, pAB828, or pAB43 plasmid was grown in batch culture in modified LB medium containing $10 \mathrm{~g} / \mathrm{L}$ tryptone, $5 \mathrm{~g} / \mathrm{L}$ yeast extract, $5 \mathrm{~g} / \mathrm{L} \mathrm{NaCl}$, and $5 \mathrm{~g} / \mathrm{L} \mathrm{K}_{2} \mathrm{HPO}_{4}$. The $\mathrm{pH}$ of the medium was adjusted to 7.0 with $5 \mathrm{M} \mathrm{NaOH}$ prior to sterilization. The culture medium was then supplemented with $1 \mathrm{~mL} / \mathrm{L}$ trace metal solution [21], $5 \mathrm{mM}$ $\mathrm{MgSO}_{4}, 4 \mathrm{~g} / \mathrm{L}$ of glucose and $100 \mathrm{mg} / \mathrm{L}$ of ampicillin. Single colonies of the AB1157 strain transformed with the desired plasmid were grown overnight at $37^{\circ} \mathrm{C}$ in $100 \mathrm{ml}$ of modified LB containing $100 \mathrm{mg} / \mathrm{L}$ of ampicillin. After overnight growth, the culture was inoculated into $5 \mathrm{~L}$ bioreactor. The fed-batch medium composition was $10 \mathrm{~g} / \mathrm{L}$ tryptone, $15 \mathrm{~g} / \mathrm{L}$ yeast extract, $2.3 \mathrm{~g} / \mathrm{L}$ $\mathrm{KH}_{2} \mathrm{PO}_{4}$, and $12.5 \mathrm{~g} / \mathrm{L} \mathrm{K}_{2} \mathrm{HPO}_{4}$, it was supplement with $2 \mathrm{~mL} / \mathrm{L}$ trace metal solution, $10 \mathrm{mM} \mathrm{MgSO}_{4}, 7.5 \mathrm{~g} / \mathrm{L}$ glucose and $100 \mathrm{mg} / \mathrm{L}$ of ampicillin. The feeding solution composition was $282 \mathrm{~g} / \mathrm{L}$ yeast extract, $141 \mathrm{~g} / \mathrm{L}$ glucose, $100 \mathrm{mg} / \mathrm{L}$ ampicillin, and $5 \mathrm{mM} \mathrm{MgSO}_{4}$.

\section{Bioreactor culture conditions}

Batch growth was performed in a $5 \mathrm{~L}$ B. Braun bioreactor equipped with data acquisition and adaptive dissolved oxygen control system. Temperature was kept at $37^{\circ} \mathrm{C}$ and $\mathrm{pH}$ was maintained at 7.0 with aqueous ammonia $(15 \%, v / v)$. The bioreactor was inoculated at $\mathrm{OD}_{600}$ of $0.2-0.3$ and the dissolved oxygen $\left(\mathrm{dO}_{2}\right)$ was measured using polarographic oxygen electrode (Mettler Toledo, Columbus, $\mathrm{OH}$ ) and controlled at 30\% air saturation. Cultures labeled as $0 \%$ were performed with limited oxygen concentration $(<0.3 \%$ air saturation $)$ by

Table 2 Plasmids and oligonucleotides used

\begin{tabular}{|c|c|c|}
\hline Plasmid, or primer & Genotype or sequence & Reference or source \\
\hline \multicolumn{3}{|l|}{ Plasmid } \\
\hline pAB49 & Same as pGFPmut3.1 plus $\triangle$ plac plus psoxS & This study \\
\hline pAB43 & Same as pGFPmut3.1 plus $\triangle$ plac & This study \\
\hline pAB828 & Same as pGFPmut3.1 plus ::IacZ-GFPmut3.1 fusion & This study \\
\hline \multicolumn{3}{|l|}{ Primers } \\
\hline GFPmut-A & ATGACCATGATTACGCCAAGCTAGTAGGCCTGATAGTAGACTCTAGAGGATCCCCGGGTA & \\
\hline GFPmut-B & TACCCGGGGATCCTCTAGAGTCTACTATCAGGCCTACTAGCTTGGCGTAATCATGGTCAT & \\
\hline SOXS-GFP-A & $\begin{array}{l}\text { TTCTGTGGATAACCGTATTACCGCCTTGAGTGAGCTGATACCGCTCGCCGCAGCCGAACG } \\
\text { ACCGAGCGCAGCGAGTCAGTGAGCGAGGAAGCGGAAGTAAATCGCTTACCTCAAGTTAA } \\
\text { CTTGAGGAATTATACTCCCCAACAGATGAATAACGAACTGAACACTGAAAAGAGGCAGAT } \\
\text { TTATGAGTAAAGGAGAAGAACTITCACTGGAGTTGTCCAATTCTTGTGAATTAGATGGTG } \\
\text { ATGTTAATGGGCACAAATITCTGTCAGTGGAGAGGGTG }\end{array}$ & \\
\hline soxS-GFP-B & $\begin{array}{l}\text { CACCCTCTCCACTGACAGAAAATTTGGCCCATTAACATCACCATCTAATTCAACAAGAATTG } \\
\text { GGACAACTCCAGTGAAAAGTTCTTCTCCTITACTCATAAATCTGCCTCTTTCAGTGTTCAGTT } \\
\text { CGTTAATTCATCTGTTGGGGAGTATAATTCCTCAAGTIAACTTGAGGTAAAGCGATTACTTCC } \\
\text { GCTTCCTCGCTCACTGACTCGCTGCGCTCGGTCGTCGGCTGCGGCGAGCGGTATCAGCTCA } \\
\text { CTCAAAGGCGGTAATACGGTTATCCACAGAA }\end{array}$ & \\
\hline
\end{tabular}


bubbling air at $0.075 \mathrm{vvm}$ and agitation of $100 \mathrm{rpm}$. One hour after inoculation, protein production was induced by the addition of $0.5 \mathrm{mM}$ IPTG to the culture with the lac promoter, or by increasing the $\mathrm{dO}_{2}$ to $300 \%$ air saturation to the culture with the soxS promoter [1]. For fedbatch cultures, the growth started at batch mode with initial volume of $4 \mathrm{~L}$, followed by predetermined exponential feeding algorithm according to the following equation [22]

$$
\mathrm{F}(\mathrm{t})=\left(\frac{\mu_{\mathrm{set}}}{\mathrm{Y}_{\mathrm{x} / \mathrm{s}}}+\mathrm{m}\right) * \frac{\mathrm{X}_{\mathrm{F}} * \mathrm{~V}_{\mathrm{F}}}{\mathrm{S}_{\mathrm{F}}} * \mathrm{e}^{\mu_{\mathrm{set}}\left(\mathrm{t}-\mathrm{t}_{\mathrm{F}}\right)}
$$

$\mathrm{F}(\mathrm{t})=$ feed rate $(\mathrm{L} / \mathrm{h}), \mu_{\text {set }}(0.351 / \mathrm{h})=$ specific growth rate, $\mathrm{Yx} / \mathrm{s}(1.28 \mathrm{~g} / \mathrm{g})=$ biomass yield on glucose estimated from exponential growth phase in batch cultures, $\mathrm{m}$ $(0.12 \mathrm{~g} / \mathrm{g} \mathrm{h})=$ maintenance coefficient, the $\mathrm{V}_{\mathrm{F}}$ and $\mathrm{X}_{\mathrm{F}}$ are the volume and biomass concentration in the bioreactor at the onset of fed-batch procedure, $S_{F}(141 \mathrm{~g} / \mathrm{L})=$ glucose concentration in the feed solution. Samples were collected at regular intervals to determine cell growth, protein production and metabolite concentrations.

\section{Analytical methods}

Cell growth was followed by measuring the $\mathrm{OD}$ at $600 \mathrm{~nm}$ (Ultrospec $3000 \mathrm{UV} /$ Visible spectrophotometer, Pharmacia Biotec); measurements were converted to dry cell weight by using a calibration curve of dried samples. Glucose concentration was determined by YSI 2700 Biochemistry Analyzer (YSI Instruments, Yellow Springs, $\mathrm{OH})$, fluorescence measurement was performed on the fluorometric plate reader SpectraMax Gemini XS (Molecular Devices) with a $485 / 515 \mathrm{~nm}$ filter set and $515 \mathrm{~nm}$ cutoff. Fluorescence intensity from fresh fermentation samples diluted 1:10 in water was analyzed in triplicate in a 96-well plate. Acetate concentration was measured by high-performance liquid chromatography (Hewlett Packard/Agilent 1100 Series, Santa Clara, CA) with an Aminex HPX-87H column (Bio-Rad Laboratories, Hercules, $\mathrm{CA}$ ) equipped with a photodiode array detector. A mobile phase of $5 \mathrm{mM} \mathrm{H}_{2} \mathrm{SO}_{4}$ was used at $0.6 \mathrm{ml} / \mathrm{min}$, run at $35^{\circ} \mathrm{C}$.

\section{Western blot analysis and ELISA}

Cell pellets from fermentation samples were washed twice in $50 \mathrm{mM}$ sodium phosphate buffer $\mathrm{pH}$ 7.4, resuspended in $300 \mu \mathrm{l}$ of the same buffer, and disrupted by sonication in a series of $4 \times 15$ seconds in a cold bath. Protein concentration was determined by the Bradford method. Samples containing $6 \mu \mathrm{g}$ protein were separated by SDS-PAGE on NuPAGE ${ }^{\circ}$ Novex $^{\circ} 4-12 \%$ Bis-Tris Gel (Life Technologies, Grand Island, NY) and transferred onto nitrocellulose membranes using the iBlot $^{\circ}$ Gel Transfer Stacks (Life Technologies, Grand Island, NY), according to manufacturer's instructions. Membranes were then incubated for $30 \mathrm{~min}$ in blocking buffer (WesternBreeze Blocker/Diluent part A and B, Life Technologies) on a rocker at room temperature. Primary mouse monoclonal anti-GFP antibody (Sigma-Aldrich, St. Louis, MO) was added for $1 \mathrm{~h}$ (diluted 1:5,000) followed by goat anti-mouse secondary antibody (KPL, Gaithersburg, MD) at 1:10,000. Detection was done using the SuperSignal West Pico Chemiluminescent Substrate detection kit (Thermo Scientific, Rockford, IL). Same cell-free extract supernatants were analyzed using a GFP ELISA kit (cat. no. AKR121; Cell Biolabs, San Diego, CA).

\section{Determination of oxidative stress on recombinant product (protein-carbonyl content)}

The presence of carbonyl groups in the protein side chains of crude protein extracts was determined by gel electrophoresis and Western blotting using Millipore's OxyBlot kit (Catalog No. S7150) [23]. Cell pellets from fresh fermentation samples of pAB828 cultures controlled at 30\% or $300 \% \mathrm{dO}_{2}$ were washed and disrupted by sonication in the presence of $50 \mathrm{mM}$ of DL-Dithiothreitol as described above. After determining protein concentrations, $8 \mu \mathrm{g}$ of total protein were used for derivatization with 2,4-dinitrophenyl hydrazine (DNPH) following manufacturer's instruction, and a parallel sample was used as negative control by substituting the derivatization-control solution for the DNPH Solution. Derivatized samples and negative controls were separated by SDS-PAGE and transferred onto nitrocellulose membranes as previously described above. Membranes were incubated for $1 \mathrm{~h}$ in blocking/dilution buffer ( $1 \%$ BSA/PBS-T) on a rocker at room temperature, followed by $1 \mathrm{~h}$ in the primary antibody solution (Rabbit Anti-DNP diluted 1:150). After two rinses with $1 \mathrm{X}$ PBS-T, the membrane was incubated for $1 \mathrm{~h}$ in the secondary antibody solution (Goat Anti-Rabbit IgG HRP-conjugated diluted 1:300). The SuperSignal West Pico Chemiluminescent Substrate detection kit (Thermo Scientific, Rockford, IL) was used for signal development.

\section{Abbreviations}

GFP: Green fluorescent protein; soxS: Transcriptional dual regulator of superoxide response regulon; FU: Fluorescence units; DW: Dry weight; $\mathrm{dO}_{2}$ : Dissolved oxygen; IPTG: Isopropyl $\beta$-D-1-thiogalactopyranoside; ELISA: Enzyme-linked immunosorbent assay.

\section{Competing interests}

The authors declare that they have no competing interests.

\section{Authors' contributions}

$A B$ designed and conducted the experiments. NM helped with molecular cloning and data interpretation. $A B$ and JS together analyzed the data and wrote the manuscript. All the authors read and approved the final manuscript.

\section{Acknowledgements}

Funding was provided by the intramural program of the National Institute of Diabetes and Digestive and Kidney Diseases, National Institutes of Health.

The authors would like to thank Mrs. D. Livnat for critical editorial assistance. 


\section{Author details}

${ }^{1}$ Biotechnology Core Laboratory, National Institute of Diabetes and Digestive and Kidney Diseases, National Institutes of Health, Bethesda, MD 20892, USA. ${ }^{2}$ National Cancer Institute, National Institutes of Health, Bethesda, MD 20892, USA

Received: 20 January 2014 Accepted: 31 March 2014

Published: 7 April 2014

\section{References}

1. Baez A, Shiloach J: Escherichia coli avoid high dissolved oxygen stress by activation of SoxRS and manganese-superoxide dismutase. Microb Cell Fact 2013, 12:23.

2. Gregory EM, Fridovich I: Oxygen toxicity and the superoxide dismutase. J Bacteriol 1973, 114:1193-1197.

3. Liochev SI, Benov L, Touati D, Fridovich I: Induction of the soxRS regulon of Escherichia coli by superoxide. J Biol Chem 1999, 274:9479-9481.

4. Damasceno LM, Huang CJ, Batt CA: Protein secretion in Pichia pastoris and advances in protein production. Appl Microbiol Biotechnol 2012, 93:31-39.

5. Maya D, Quintero MJ, Munoz-Centeno MC, Chavez S: Systems for applied gene control in Saccharomyces cerevisiae. Biotechnol Lett 2008, 30:979-987

6. Lee YJ, Jung $\mathrm{KH}$ : Modulation of the tendency towards inclusion body formation of recombinant protein by the addition of glucose in the araBAD promoter system of Escherichia coli. J Microbiol Biotechnol 2007, 17:1898-1903.

7. Ferenci T: Hungry bacteria-definition and properties of a nutritional state. Environ Microbiol 2001, 3:605-611.

8. Menart V, Jevsevar S, Vilar M, Trobis A, Pavko A: Constitutive versus thermoinducible expression of heterologous proteins in Escherichia coli based on strong PR, PL promoters from phage lambda. Biotechnol Bioeng 2003, 83:181-190.

9. Andersen JB, Sternberg C, Poulsen LK, Bjorn SP, Givskov M, Molin S: New unstable variants of green fluorescent protein for studies of transient gene expression in bacteria. Appl Environ Microbiol 1998, 64:2240-2246.

10. Figge J, Wright C, Collins CJ, Roberts TM, Livingston DM: Stringent regulation of stably integrated chloramphenicol acetyl transferase genes by $E$. coli lac repressor in monkey cells. Cell 1988, 52:713-722.

11. Lee SK, Keasling JD: Propionate-regulated high-yield protein production in Escherichia coli. Biotechnol Bioeng 2006, 93:912-918.

12. Caspeta L, Flores N, Pérez NO, Bolívar F, Ramírez OT: The effect of heating rate on Escherichia coli metabolism, physiological stress, transcriptional response, and production of temperature-induced recombinant protein: a scale-down study. Biotechnol Bioeng 2009, 102:468-482.

13. Hughes DE, Curtis JE, Khosla C, Bailey JE: A new oxygen-regulated promoter for the expression of proteins in Escherichia coli. Biotechniques 1989, 7:1026-1028.

14. Valdez-Cruz NA, Caspeta L, Perez NO, Ramirez OT, Trujillo-Roldan MA: Production of recombinant proteins in $\mathrm{E}$. coli by the heat inducible expression system based on the phage lambda $\mathrm{pL}$ and/or $\mathrm{pR}$ promoters. Microb Cell Fact 2010, 9:18.

15. Lee SK, Keasling JD: A propionate-inducible expression system for enteric bacteria. App Environ Microbiol 2005, 71:6856-6862.

16. Dalle-Donne I, Rossi R, Giustarini D, Milzani A, Colombo R: Protein carbonyl groups as biomarkers of oxidative stress. Clin Chim Acta 2003, 329:23-38.

17. Barrick D, Villanueba K, Childs J, Kalilo R, Schneiderl TD, Lawrence CE, Gold L, Stormo GD: Quantitative analysis of ribosome binding sites in E. coli. Nucleic Acids Res 1994, 22:1287-1295.

18. Hashim SS, Mohamed AR, Bhatia S: Oxygen separation from air using ceramic-based membrane technology for sustainable fuel production and power generation. Renew Sust Energ Rev 2011, 15:1284-1293.

19. Shang L, Tian PY, Kim NJ, Chang HN, Hahm MS: Effects of oxygen supply modes on the production of human growth hormone in different scale bioreactors. Chem Eng Technol 2009, 32:600-605.

20. Imlay JA, Linn S: Mutagenesis and stress responses induced in Escherichia coli by hydrogen peroxide. J Bacteriol 1987, 169:2967-2976.

21. Bauer S, Shiloach J: Maximal exponential growth rate and yield of E. coli obtainable in a bench-scale fermentor. Biotechnol Bioeng 1974, 16:933-941.
22. Strandberg $L$, Andersson L, Enfors SO: The use of fed batch cultivation for achieving high cell densities in the production of a recombinant protein in Escherichia coli. FEMS Microbiol Rev 1994, 14:53-56.

23. Levine RL, Williams JA, Stadtman ER, Shacter E: Carbonyl assays for determination of oxidatively modified proteins. Methods Enzymol 1994, 233:346-357.

doi:10.1186/1475-2859-13-50

Cite this article as: Baez et al:: Production of recombinant protein by a novel oxygen-induced system in Escherichia coli. Microbial Cell Factories 2014 13:50.

\section{Submit your next manuscript to BioMed Central and take full advantage of:}

- Convenient online submission

- Thorough peer review

- No space constraints or color figure charges

- Immediate publication on acceptance

- Inclusion in PubMed, CAS, Scopus and Google Scholar

- Research which is freely available for redistribution 